\title{
A prisão dos ébrios, capoeiras e vagabundos no início da Era Republicana
}

\author{
Myrian Sepúlveda dos Santos
}

\section{Introdução}

Em 1893, durante o governo de Floriano Peixoto, um decreto legislativo autorizou a criação de um estabel ecimento voltado para a correção, pelo trabalho, dos vadios, vagabundos e capoeiras que fossem encontradosnaC apital Federal. ${ }^{1}$ A partir deste decreto, uma Colônia Correcional foi instalada na Ilha Grande, no ano seguinte. D ois anos após ser criada, contando com dificuldades econômicas e precariedade de pessoal, a Colônia foi fechada sob o argumento de que o estabelecimento era completamente incapaz de cumprir os objetivos estabelecidos pela lei. Em 1903, em função de um novo decreto, a "Colônia Correccional de D ous Rios" voltou a ser instalada, no mesmo local, sendo que desta vez com um aparato administrativo bem mais complexo. Ainda assim, foram vários os problemasenfrentadose, em 1907, avaliações oficiais reproduziam o diagnóstico de 1895; a Colônia passou, então, por uma reformulação geral para que se adequasse aos propósitos formulados.

Paraalguns dosautores queinvestigaram as instituições disciplinadoras que se formaram nos primeiros anos da República, ${ }^{2}$ o sistema legislativo e institucional que foi instalado neste período cumpriu um papel de destaque na repressão às classes subordinadas. ${ }^{3} \mathrm{~N}$ ão há nenhuma intenção aqui de se negar que o sistema carcerário foi forjado paral elamente ao estabelecimento de um Estado, que, embora fundado no discurso democrático e liberal, tenha sido responsável por práticas repressivas e excludentes. 0 objetivo deste artigo, entretanto, éinvestigar a relação entre normas instituídas através do sistema legislativo ejudiciário e a aplicação empírica destas leis, uma vez que esta análise pode contribuir para os estudos sobre direito e cidadania. 
0 que será apresentado, a seguir, éque, nas duas tentativas de implementação da Colônia Correcional, houve um distanciamento profundo entreum conjunto de propostas correcionais edisciplinares, vigente tanto no Brasil, como na Europa e Estados Unidos, e as práticas desenvolvidas nos estabelecimentos penais analisados. Em questão está a continuidade ou não de padrões de assi milação das normas instituídas, pois se o sistema penal não obteve sucesso em legitimar-se segundo as normas que o constituía, precisamos investigar se é possível correlacionar as práticas estabelecidas ao discurso moral evalorativo daqueles responsáveis por implementar alei.

A documentação que aqui será analisada, consiste, por um lado, de debates travados entre membros da elite dirigente, bem como de decretos do legislativo e do executivo relativos à criação efuncionamento da Colônia Correcional $\mathrm{D}$ ois Rios. A análise de relatórios ministeriais, de comissões fiscalizadoras, de diretores da Colônia, e de discursos de época, por outro lado, nos permite analisar as dificuldades de implementação dos decretos promulgados.

Antes de passar à análise propriamente dita do processo de criação e implementação da Colônia, gostaria de mostrar, primeiro, que estabelecimentos correcionais não eram uma novidade no país. A criação de instituições penais voltadas para a reabilitação dos sentenciados já vinha ocorrendo no país durante o século XIX, segundo concepções muito próximas daquelas que orientaram as práticas desenvolvidas em $D$ ois Rios. A segunda observação é que a prisão de vadios, vagabundos e capoeiras representou ampliação de processo de modernização da cidade, uma vez que as autoridades passavam a colocar em reclusão indivíduos que representavam ameaça à ordem pública, mesmo que eles não pudessem ser acusados de terem realizado qualquer crime.

\section{As primeiras casas correcionais}

(...) a prisão solitária, tal como a imagino, não significa segregação, pois o detento mantém comunicações freqüentes com os guardas emesmo com as pessoas honestas e caridosas que demonstram interesse pela sua recuperação. Ele não está separado de sua família, que ele pode ver sob inspeção e 
com a permissão da administração. Ele não está em um calabouço, mas em um aposento sadio, arejado, com aquecimento, ondeele ébem alimentado, bem vestido, onde ele trabal ha e pode ler e escrever. ${ }^{4}$

É importante voltarmos um pouco atrás no tempo, para que possamosmelhor contextual izar o decreto quefora sancionado, em 1893, criando a Colônia Correcional de D ois Rios (CCD R). Em uma sociedade hierarquizada, as penas variavam segundo a condição social do indivíduo que praticara a infração e da vítima, caracterizando-se, portanto, o sistema de leis por uma pluralidade de penas distintas que poderiam ser atribuídas ao mesmo crime. $\mathrm{N}$ as cadeias públicas, era comum a convivência entre todos aqueles que aguardavam julgamento, bem como a superpopulação e condições indizíveis de sobrevivência, tal a insalubridade e abafamento das instalações. Além disso, as penas muitas vezes implicavam em tortura física. No Brasil colonial, as práticas punitivas incluíam esquartejamentos, amputações, açoites, torturas físicas diversas e a marca de ferro quente. $A$ imputação de penas não tinha a função de recuperar ou integrar o preso à sociedade e pouco se recorria ao encarceramento.

$\mathrm{N}$ a Europa medieval, as prisões eram utilizadas, fundamentalmente, para que o cumprimento das penas fosse possível; elas eram uma garantia de que os acu sados pagariam suas multas e receberiam seus castigos corporais. A partir de meados do século dezoito e início do século dezenove, entretanto, as prisões tornaram-se um fim em si mesmas, ou seja, uma pena ou um castigo. ${ }^{5} \mathrm{C}$ om a chegada da Família Real, no Rio de Janeiro, em 1808, os elos entre a antiga colônia e a Europa se estreitam. As autoridades portuguesas procuraram ampliar o sistema de vigilância sobre as ruas da cidade, criando uma força policial organizada. A Guarda Real de Polícia passou a vigiar de modo mais regular o movimento citadino. A preocupação com a remodelação do sistema carcerário, estabelecendo que cadeias não só deveriam ser seguras, limpas e bem arejadas, mas também proporcionar a separação dos réus, que seriam julgados conforme natureza e circunstâncias de seus crimes, consolidou-se na C onstituição de $1824 .{ }^{6}$

$\mathrm{N}$ o Brasil, foram freqüentes as viagens dos juristas, políticos e demais autoridades a estabelecimentos penitenciários da Europa e Estados U nidos. D urante o século dezenove, tanto na Europa quanto nos Estados U nidos, o encarceramento vinha sendo adotado como principal meio de 
punição, deixando de ser apenas instrumento destinado a garantir a imputação das penas. D ois modelos penitenciários norte-americanos, o sistema "decongregação" deAuburn (N ova lorque) eo sistema "de isolamento" da Filadélfia (Pensilvânia), traziam as grandesinovações defendidas pelos progressistas da época. ${ }^{7}$

Alexis de Tocqueville fez uma série de viagens oficiais entre $1831 \mathrm{e}$ 1832, visitando diversossistemas carcerários nos Estados Unidos, eenviando relatórios detal hadosao M inistro do Interior deseu país, com avaliações detal hadas sobre os sistemas penitenciários encontrados. N os anos subseqüentes escreveu reiteradamente sobre o tema, comparando os sistemas carcerários norte-americanos com o sistema francês. Em 1838, com base em suas viagens anteriores, analisou os dois regimes carcerários rivais nos Estados U nidos. Segundo ele, havia o regime que seguia o padrão da "Auburn StatePrison" (N ova Iorque), ou seja, que permitia queos detentos trabalhassem reunidos, mas em silêncio, duranteo dia, e os separavaànoite. Estes eram encontrados nas prisões de 0 ssining (também conhecida como Sing Sing) edeBoston, visitadas por ele. $\mathrm{H}$ avia também as prisões queisolavam os detentos dia e noite, de acordo com o modelo da Filadélfia. No primeiro, apontou o forte regime disciplinar eo aspecto lucrativo das prisões, resultante do trabal ho coletivo. Para que pudessem controlar o conjunto de detentos durante dia, os diretores e guardas penitenciários - que estavam sob intenso sistema de pressão, pois suas vidas estavam em jogo detinham praticamente toda a responsabilidade sobre a manutenção da disciplina, cabendo a eles decidir sobre os meios convenientes a serem utilizados, inclusive castigos corporais, no que eram apoiados pela opinião pública. Segundo Tocqueville, a sociedade francesa não aceitaria com facilidade este sistema e seus castigos corporais. No segundo modelo, o custo para o Estado era maior, pois as celas individuais eram mais amplas eo traba Iho isolado dos detentos menos lucrativo, mas, segundo ainda Tocqueville, nestas prisões havia o poder não só deintimidar, mas dereformar o detento moralmente. ${ }^{8}$ Assinal ou ainda que enquanto no primeiro caso o índice de mortalidade entre os presos era baixíssimo, no segundo ele era maior. Ainda assim, Tocqueville defendeu a implementação do sistema da Filadélfia na França, e nos demais países europeus. ${ }^{9}$ 
Em 1830, o primeiro Código Criminal foi promulgado no Brasil, apontando um movimento de adaptação da sociedade brasileira às novas tendências disciplinares. Procurava-se, no que diz respeito às leis, substituir a herança colonial, oriunda das antigas 0 rdenações do Reino (Código Filipino), por este novo Código Penal. A criação de um conjunto de leis estipulando com precisão qual seria a pena a ser atribuída a cada tipo de crime tornou-se uma condição importante para o novo modo de governar, pois os crimes passavam a ser julgados segundo critérios universalistas, que tinham como princípio o conceito do indivíduo contemplado pelo livre-arbítrio. Segundo o Código, a prisão passava a ser o principal meio de punição, tendo como objetivo a recuperação do detento ea diminuição da reincidência de atos criminosos. 0 castigo deveria ser proporcional ao crime, determinado pelas leise jamais um ato de violência de um ou vários homens sobre um indivíduo. Era fundamental separar os prisioneiros de acordo com a idade, sexo e natureza do crime. $N$ ão se tratava tão somente de isolar o criminoso do convívio social, mas, a partir deentão, de dar meios para que ele pudesse substituir a sentença inicial por liberdade através da aquisição da razão e da moral. Ao longo do século, foram substituídas, gradativamente, as antigas penas, consideradas cruéis e degradantes para os indivíduos, pelo encarceramento. No que diz respeito aos modelos de encarceramento, a proposição do trabal ho coletivo triunfou.

As primeiras $\mathrm{C}$ asas $\mathrm{C}$ orrecionais foram instaladas no Brasil, em me ados do século XIX, de forma a atender às mudanças ocorridas na legislação. ${ }^{10} \mathrm{~A}$ C asa Correcional do Rio de aneiro foi inaugurada em 1850, com celas individuais, oficinas, pátios e demais dependências necessárias à implementação das penas que estipulavam o trabalho intra-muros. Segundo Salla, a C asa de Correção de São Paulo, inaugurada em 1852, foi em grandemedida inspirada pelo sistema deAuburn. A lei penal trazia regulamentos detal hados de práticas a serem implementadas no dia-a-dia dos presos: horários das diferentes atividades, as rotinas de trabal ho, as penas disciplinares a serem aplicadas em situações de rebeldia, vestuário, alimentação, serviço de enfermaria, vida religiosa e organização administrativa. ${ }^{11}$

D urante o Império, entretanto, em que pese os debates entre parlamentares, códigos eleis promul gados, bem como a criação de casas correcionais, as formas coloniais de encarceramento continuaram a ser predo- 
minantes. As explicações para o descompasso entre a formulação e a aplicação da lei são várias. H avia, sem dúvida, uma tensão interna às próprias leis, uma vez que elas aboliam os castigos que degradavam os corpos e humilhavam as almas, mas os mantinham como válidos na punição de escravos. Além disso, era necessário fortalecer os sistemas legislativo e judiciário, para que el es pudessem controlar a prática dos policiais e do carcereiro, pois a sociedade colonial era marcada pelo mandonismo local. Embora astesesliberaisfossem predominantesnalegislação a partir de 1830, pois decretavam a descentralização do sistema penal e val orizavam os institutos judiciários em detrimento dos policiais, elas ainda eram instáveis. Em 1841, por exemplo, leis conservadoras limitaram os poderes dos juízes de paz, ampliando as atribuições de autoridades policiais. D e qualquer forma, os movimentos sociais e políticos, ocorridos a partir 1870, fortaleceram as propostas mais liberais. Asnormas foram uniformizadas, sendo 0 poder local limitado a decisões sobre os regimes e regulamentos das prisões. ${ }^{12}$ Entre as mudanças ocorridas, em 1871, podemos citar a implementação de medidas que procuravam fortalecer um Estado de direito, como a ampliação do direito ao habeas corpus, a restrição da prisão preventiva por autoridades policiais, e a diminuição da interferência de policiais nos processos de crimes comuns. ${ }^{13}$

Podemos considerar também que a construção do novo sistema de estabelecimentos penitenciários implicava na adaptação de um ideário liberal aos costumes, práticas eidéias locais, ainda muito influenciados pela escravidão. N ão havia no país prisões adequadas aos novos modelos em número suficiente para que as leis fossem cumpridas. As cadeias encontravam-se situadas no centro da vida urbana, ocupando os mesmos prédios que abrigavam as $\mathrm{C}$ âmaras M unicipais. $\mathrm{O}$ s presos não se encontravam isolados nem uns dos outros, nem da população, efugiam freqüentemente com o suporte que obtinham de fora da cadeia. Segundo relatos de época, o estado das cadeias em todo o país, inclusive nas capitais das províncias, continuava precário. D entre os principais problemas apontados, destacavam-se a falta de espaço, a reunião de presos de diferentes idades e condições em um só local, a ociosidade constantee o estado deplorável das condições de higiene a que eram submetidos os detentos. Já, nesta época, denunciava-se que os cárceres existentes, ao invés deregenerar o preso, ten- 
diam a corrompêlo ainda mais, aumentando a incidência do crime. As rebeliõestambém existiam. Em 1883, houveuma rebelião detrezentos presos da C asa de D etenção do Distrito Federal, quando, encarcerados em número muito superior à capacidade do prédio e sob condições precárias, destruíram celas, dependências e equipamentos.

Com a proclamação da República, o país voltou-se novamente para a tentativa de implementação de um sistema carcerário nos moldes da épo$\mathrm{ca}$, que deveria substituir a degradação do detento e ter como base a sua recuperação. 0 país parecia já ter as condições necessárias para tal, pois medidas liberais que apontavam neste sentido vinham sendo defendidas ao longo de grande parte do século dezenove. Entretanto, é interessante notar que, já na década de 70, as medidas voltadas para o encarceramento em celas individuais, dia e noite, eram criticadas por diversas autoridades por ser 0 isolamento considerado ineficiente e "pouco próprio para os homens de nossa raça, costumes e condiç̧ões climatéricas do país, em que vivemos". ${ }^{14}$

0 Código de 1890 reiterou os princípios básicos do Código de 1830, aprofundando 0 sentido da reforma já iniciada. Ele reduziu penas como 0 banimento, o degredo e o desterro, que não eram mais consideradas eficientes, eaboliu a pena de gal és, em que os presos trabalhavam com correntes. 0 sistema de prisão adotado foi fortemente influenciado pelo sistema progressivo ou irlandês, que estabelecia estágios sucessivos de encarceramento, com a finalidade de recuperar os sentenciados. Estabeleceu-se no Brasil um sistema de punição decrescente, em que o sentenciado de bom comportamento tinha possibilidade de diminuir sua pena; tornando-se possível alcançar liberdade condicional após cumprimento de prisão em isolamento e em regimes semi-abertos propiciados por colônias agrícolas. A lei estabelecia regulamentos detal hados, que permitiam ao recluso a educação e a utilização do trabalho de maneira produtiva. 0 preso deveria ser pago por seu trabalho sob a forma de um pecúlio a ser recebido por ocasião da liberdade. 0 conjunto de leis trouxe ainda medidas práticas, como dotações orçamentárias, que procuravam tornar factível a implementação das leis promulgadas.

A criação da Colônia Correcional de D ois Rios surgiu, nestecontexto, representando a tentativa do governo republicano de romper com a 
herança escravista, melhorar as condições prisionais e estabelecer regulamentos detalhados, possibilitando a recuperação moral do recluso a partir da educação e da utilização do trabalho de maneira produtiva. Procuravase combater as práticas punitivas sobre o corpo e o poder dos carcereiros. Através dos relatórios ministeriais, como veremos, é evidente que se acreditava que médicos e educadores, através da técnica e da ciência, seriam capazes de recuperar moral mente os criminosos. A criação da Colônia foi resultado, também, deuma outra novidadeintroduzida pela legislação republicana: a ampliação do encarceramento, que passa a atingir amplos setores da sociedade, com objetivos correcionais.

\section{Mendigos e ébrios, vadios e capoeiras}

A instalação da Colônia Correcional em D ois Rios está associada a uma ampliação do processo deencarceramento, tornando maiores as penas estabelecidas no Código Penal de 1890 e dando os primeiros passos nasistematização de um regime disciplinar nos cárceres. ${ }^{15}$

No final do século XIX, com a abolição da escravatura, negros libertos, em grande número, deslocavam-se para as cidades à procura de oportunidades equando lá chegavam não conseguiam ser absorvidos em atividades remuneradas. 0 crescimento do número de imigrantes, vindostanto do interior do Brasil, quanto do exterior também contribui para o crescimento urbano desordenado. C apoeiras, queeram utilizados tanto por liberais, como por conservadores como uma milícia para-militar, ficaram na República fora do controle das autoridades. C apoeiras, negros alforriados, imigrantes e pobres eram apontados pelos chefes de polícia como sendo os principais responsáveis pelo número cada vez maior de roubo, latrocínio e prostituição. A repressão dos capoeiras contou com a ação desmedida de forças policiais, queobtinham o apoio da imprensa edemoradores declasse média que contribuíam delatando os nomes e paradeiro dos capoeiras. ${ }^{16}$

No Código Penal de 1890, havia artigos que tornavam mendigos, ébrios, vadios e capoeiras em contraventores sujeitos à prisão celular. Para os que fossem maiores de 21 anos, ficava estabelecida a prisão em celas, quevariava de 5 dias a 4 meses. 0 s menores, entre 14 e 21 anos, deveriam ser recolhidosa estabelecimentosdisciplinaresindustriais. A repressão maior 
era indubitavelmente contra os vadios e capoei ras reincidentes. $D$ eacordo com artigos 399, 400 e 401, eles deveriam ser recolhidos por 1 a 3 anos em colônias penais, em ilhas marítimas ou nas fronteiras do território. Aqueles que fossem estrangeiros reincidentes seriam deportados. ${ }^{17}$

A República procurava introduzir com suas leisum respeito maior ao indivíduo, principalmente à proteção à integridade do corpo físico, atributo da modernidade. As leis proscreveram medidas penais que tinham por base a represália, ou seja, o direito da vítima revidar com dano igual ao recebido. Entretanto, se, por um lado ampliava-se a participação dos indivíduos enovasformas de cidadania, por outro, passava-sea responsabilizar o indivíduo por falta de recursos, mendicância e embriaguez, e restringiasebrutalmentea noção de espaço público, colocando para foratodosaqueles que não Ihe eram gratos.

Passou-se a considerar necessário o encarceramento e a correção de indivíduos que optassem por uma forma de vida ou um modo de ser que não se coadunassem às normas estabelecidas, mesmo que esta opção não implicasseem danosa outrem. Caso isso acontecesse, as penasaumentavam. ${ }^{18} \mathrm{O} \mathrm{s}$ mendigos, bêbados e vadios descritos pela lei eram aqueles indivíduos que escolhiam a miséria e vício, uma afronta à moral eaos bons costumes. N ão eram colocados na cadeia os pobres em geral, mas os pobres que não tinham "optado" pelo trabalho e pelos bons costumes. Já os capoeiras repre sentavam a opção pela rebeldia. A prática da capoeiragem envolvia guardas nacionais, praças do exército e da armada, artesãos, e indivíduos oriundos das diversas camadas sociais. ${ }^{19}$ Ela foi considerada crime porque representava uma ameaçava à segurança física dos demais cidadãos. 0 aumento da repressão sobre a capoeira e a deportação de seus praticantes foi uma das primeiras medidas tomadas pelo novo regime republicano. A falta de recursos próprios passou a ser responsabilidade do indivíduo. Além disso, a lei colocava na prisão àqueles que vagavam pela cidade e não tinham "meios de subsistência," mas não penalizava aqueles que tinham fortuna própria. M esmo crianças podiam ser culpabilizadas e cumprir penasiguais às dos adultos. Agora não só os capoei ras e vadios maiores de 21 anos eram enviados para a prisão por longo período, mas "indivíduos de qualquer sexo e idade (...) sem meios de subsistência". 
Para implementar estas mudanças, o segundo governo republicano contou com uma série de intervenções violentas das autoridades constituídas. Policiais derrubaram cortiços, já prenunciando uma série de medidas, que al guns anos depois caracterizariam o autoritarismo do "bota-abaixo" do governo Rodrigues Alves. N esta ocasião, o prefeito do Rio de Janeiro entre 1903 a 1906, Pereira Passos, foi responsável por empreendimentos saneadores e modernizadores, considerados pela população como ditatoriais. A população assistiu com cautela, por exemplo, as proibições à circulação de vacas, porcos e cães vadios pelas ruas, a cuspir no bonde, ao descuido com fachadas, à exposição de carne na porta dos açouguese ao desfile dos blocos de carnaval sem autorização. Por ocasião da obrigatoriedade da vacina contra a febre amarela, a cidade foi palco de uma das revoluções populares mais significativas de sua história. ${ }^{20}$

O utra observação importante é que, no início da República, apesar do texto da lei, do discurso de parlamentares e demais autoridades sobre a importância do papel reabilitador do cárcere, o tratamento dado aos presos manteve-sebem distante daqueledescrito nos modelos prisionais defendidos. Segundo Soares, os capoeiras, que antes ficavam na C asa de D etenção, passaram aser levados para a fortaleza deSanta C ruze delá deportados para a ilha Fernando de $\mathrm{N}$ oronha. A fortal eza, entretanto, associava a rotina disciplinar, que era semel hanteà de um quartel, aos castigos corporais. 0 trabal ho dos presos era servil; eles carregavam água e faziam serviços de faxina de toda ordem. Por uma falta mínima, os detentos recebiam uma pranchada com uma espécie de espada de madeira. 0 transportenos porões dos navios é sempre descrito como um pesadelo, em que homens eram jogados em grandenúmero em um pequeno espaço, sem quaisquer condições de higiene e privacidade. Em Fernando de N oronha, o tratamento arbitrário e desumano repetia-se, estando muito longe de ser um estímulo para regeneração. A surra com vara de gameleira, que deixava marcas nas costas, aparece citada em vários depoimentos. ${ }^{21}$

Em suma, a instal ação da nova colônia correcional tinha como obje tivo prender e educar os que perambulavam pelas ruas da capital federal dando a eles um ofício e adaptando-os aos padrões de conduta da época. Fortaleceu-se a política civil e o treinamento da força pública. Constituiuse uma rede carcerária sutil, graduada, baseada nos ensinamentos técnicos 
ecientíficos, capaz de incorporar também as "classes perigosas. ${ }^{22 " ~ D ~ i v e r s a s ~}$ outras instituições, como hospícios e institutos disciplinares para menores, foram criadas no período segundo as mesmas premissas. Em que pese a constituição deste novo arcabouço institucional, mantiveram-se presentes no processo disciplinar práticas herdadas do período escravista.

\section{A primeira colônia correcional: 1894-1897}

A primeira Colônia Correcional criada em D oisRios, teve, portanto, como objetivo, recolher homens, mulheres e crianças que fossem presos pelas forças policiais e jul gados pelas cortes como menores abandonados, bêbados, jogadores, desordeiros, ratoneiros, vadios, vagabundos, capoeiras e mendigos. A lei de 1893 destinava à Colônia não só capoeiras e vadios maiores de 21 anos, mas indivíduos de qualquer idade pertencentes ao que se compreendia na época como "classes perigosas". Também substituía a pena celular de poucos dias para bêbados e mendigos pela residência na Colônia Correcional por seis meses a dois anos. A lei estipulava o trabalho agrícola e o estabelecimento de oficinas, de modo a serem aproveitadas as aptidões e serviços dos 'condenados', tendo em consideração o sexo ea idade; o pagamento de cada correcional que receberia na saída o pecúlio formado; e providenciava, ainda, que o governo dispusessedeaté87.000:000\$000 para a boa execução das demandasfeitas.

Em 1894, as leis procuraram regulamentar o cotidiano da vida no cárcere; foi sancionado um regulamento extenso e detalhado, capaz de determinar praticamente todos os passos de funcionários e daqueles que para ali eram enviados. ${ }^{23} \mathrm{O}$ condenado, ao chegar à Colônia, seria apresentado ao diretor, matriculado em livro próprio, receberia um número e três mudas de roupa devidamente marcadas com o mesmo número. $0 \mathrm{~s}$ detentos seriam destinados ao trabalho que melhor se adaptasse as suas aptidões. A vestimenta dos homens seria composta por uma calça e jaque ta azul de algodão, camisa branca de algodão, barrete de lã ou chapéu de pal ha, sapatos grossos e cinturão de vaqueta com fivela. 0 uniforme das mulheres era similar: camisa e saia de al godão, vestido de riscado encorpado azul, sapatos grossos, barrete de lã e também cinturão de vaqueta com fivela. 0 diretor e seu ajudante seriam responsáveis pelo bom andamento 
do estabelecendo, cabendo, inclusive, a eles apresentar um relatório sobre o estado da Colônia e progresso obtido na correção dos colonos ao Chefe de Polícia. N esteprimeiro regulamento não havia qualquer norma relativa à separação de homens, mulheres e crianças, ou mesmo à separação dos condenados segundo o crime cometido.

0 trabalho começaria demanhã, logo após o toquede despertar, seria suspenso na ocasião do al moço e do jantar, efinalmente cessaria ao toque da ceia. O shorários das refeições seriam estabelecidos pelo diretor da Colônia. $\mathrm{H}$ averia um mestre para cada oficina e um chefe para cada turma de 25 trabal hadores agrícolas. 0 s produtos de oficinas e lavouras seriam vendidoseo val or arrecadado seria revertido para a manutenção da instituição e para a formação do pecúlio dos trabalhadores. 0 regulamento refere-se ainda a arrendamentos ou vendas a preços módicos de lotes afastados a colonos já regenerados, que quisessem cultivar a terra por conta própria. Em tais lotes poderia o G overno mandar construir casas provisórias, cujo valor seria incluído no preço das vendas ou arrendamentos. 0 Governo poderia ainda permitir que os colonos empregassem mediante pagamento de salário, al guns condenados para trabalharem em seus lotes.

0 papel do médico seria destacado na Colônia. Ele teria como função não só exercer a prática da medicina, controlar remédios ealimentos, mas também educar os colonos, propiciando-Ihes um aprendizado moral. Além de ser professor, o médico também seria responsável por assumir interinamente a direção da Colônia, em caso de impedimento do diretor e seu ajudante. Sobre penas disciplinares, ficava estabelecido que, se cometessem faltas, os condenadosficariam sujeitos a trabal ho solitário com tarefa; prisão a pão e água; isolamento em cela escura. 0 condenado que fosse recapturado após tentativa de fuga teria como pena um mês em cela escura. 0 regulamento continha, ainda, disposições bem minuciosas sobrefornecimento de gêneros, direito a correspondências, instalação de oficinas, visitas e diversos outros itens. Sobre as correspondências, seria permitido aos condenados remetêlas erecebêlas sob permissão do diretor. Finalmente, dispunha o decreto-lei que a Colônia seria inspecionada anualmente por uma comissão composta por três membros, um do M inistério da Justiça e N egócios Interiores, outro do Tesouro $\mathrm{N}$ acional e um terceiro da 
Repartição de Polícia. É justamentea partir destes relatórios que podemos ter alguma noção de como este regulamento foi cumprido.

Temosmuito pouca informação de como foi o dia-a-dia desta primeira Colônia. Entretanto, segundo relatório de 1896, ${ }^{24}$ relativo às atividades do ano precedente, ficamos saben do que a Colônia fora instal ada em setembro de 1894, na antiga Fazenda de D ois Rios, I Iha Grande, havendo deficiência de pessoal habilitado, materiais indispensáveis e exigüidade de verbas. ${ }^{25} \mathrm{~A}$ Colônia utilizou instal ações já existentes da fazenda. 0 prédio da administração foi restaurado, bem como as antigas senzal as, que passaram a acomodar uma pequena enfermaria e uma farmácia. Foram feitos "arranjos necessários" para o funcionamento de dormitórios para correcionais, alojamento policial, almoxarifado, três casas para oficinas e moradia de feitores de turma. 0 relatório refere-se ainda a obras relativas à canal ização da água e à construção de diversos estabelecimentos para abrigar secretaria, padaria, açougue, refeitórios, cozinha, xadrez, banheiro, bem como residências para ajudante do diretor, médico, escrivão eal moxarife. 0 próprio ministro declara ter redigido uma circular aos juízes recomendando a observância da lei e o envio a D ois Rios dos indivíduos processados nos termos do decreto citado. No final de 1895, a Colônia tinha sob seus cuidados apenas 6 homens e 13 mulheres.

0 relatório ministerial de 1896 nosinforma queos regulamentos não foram cumpridos e que devido a queixas contra a administração da Colônia, esta foi fechada em 18 de novembro de 1896:

M uito útil seria que os juizes competentes, no interesse da correção, pelo trabal ho dos vadios, vagabundose capoeiras, (...), cumprissem regularmente o disposto (...) que destina a Colônia Correcional à reclusão dos indivíduos de qualquer sexo e idade, condenados em virtude e para o efeito do art. $1^{\circ}$ da citada lei.

0 relatório ministerial do ano seguinte é mais claro ao condenar a instalação da Colônia como uma experiência malograda, "um ensaio infeliz e discorde do nosso sistema penal". ${ }^{26} \mathrm{~A}$ Colônia foi fechada e com isso novo impasselegal era criado, poisnão havia maiso local, isto é, uma colônia correcional, onde a pena aplicada às "classes perigosas" pudesse ser cumprida. 0 tratamento correcional a ser dado aos menores também perma- 
necia sem possibilidades de realização, pois estes voltavam a ser enquadradosno art $399 \S 2^{\circ}$ do Código Penal, que estabelecia queeles deveriam ser recolhidos em estabelecimentos disciplinares industriais, quetambém não existiam.

M algrado o insucesso da primeira tentativa, continuava a necessidade de um estabelecimento que fosse capaz de receber mendigos e capoeiras conforme previsto pela lei. Em 1899 foi aprovada uma lei complementar ao Código Penal, que visava dar maior agilidade no julgamento e punição dos contraventores. A partir daquela data, os delegados de polícia passavam a ter a função eo poder de produzir os processos por contravenção. ${ }^{27}$ No relatório do Chefe de Polícia, D r. Antonio Augusto Cardoso de Castro, de 1904, fica evidenteque para as forças policiais era de crucial importância o estabelecimento da Colônia Correcional:

Ao assumir o exercício de Chefe de Polícia, logo compreendi que, sem o restabelecimento da Colônia Correcional, todos os meus esforços seriam improfícuos para libertar o Rio de aneiro desses maus elementos que representam uma ameaça permanente à ordem jurídica, a que mais tarde, pela impunidade, se habituam a agredir de outra maneira mais positiva. ${ }^{28}$

Podemos observar, portanto, um movimento voltado para a criação de uma colônia correcional, nos moldes dos padrões prisionais modernos, que se deparava, entretanto, com um grande número de dificuldades em sua realização. D esta primeira Colônia, podemos apenas constatar que houve um grande distanciamento entre as leis e normas sobre instalações carcerárias e o funcionamento destas.

\section{A segunda colônia correcional: 1903 - 1955}

Confio que em tempo relativamente muito curto se conseguirá, de par com a regeneração dos transviados sociais ou enfermos moraisque para aqui vêm, alguma renda resultante dos recursos naturais de que dispõe a Colônia, bem como dos trabalhos dos internados, inteligentemente aproveitados. ${ }^{29}$

No dia 9 defevereiro de1903, agorajáno governo de RodriguesAlves, a Colônia Correcional de D ois Rios foi instalada novamente, a partir da 
promulgação, no ano anterior, de uma lei voltada para a reforma policial do D istrito Federal. ${ }^{30}$ Esta lei reiterava os termos do decreto anterior, autorizando a criação de colônias correcionais para reabilitar, pelo trabalho e educação, indivíduos que fossem considerados mendigos, vagabundos ou vadios, capoeiras, ébrios habituais, jogadores, ladrões e viciosos. Procurava-se, também, que a C olônia rendesse al gum lucro e se auto-sustentasse. O s regulamentos aprovados eram cada vez mais detalhados. ${ }^{31} \mathrm{M}$ as, novamente, pelos relatórios existentes das comissões inspetoras e de antigos diretores, nos damos conta de quea C olônia que foi instalada esteve muito longe de reproduzir a racional idade expressa nas leis, decretos e normas regulamentares. U m relatório minucioso do capitão Francisco Siqueira do Rego Barros, diretor da Colônia de março de 1905 a fevereiro de 1906, nos dá uma dimensão aproximada do hiato que se formava. ${ }^{32}$

Pelo regulamento, o quadro de funcionários da Colônia deveria ser composto de um conjunto grande de profissionais especializados, desde 0 diretor e o médico até cozinheiros e serventes, sendo que estes últimos deveriam ser contratados no número que fosse necessário. Entretanto, tal como acontecera na administração anterior, um dos grandes problemas da administração dizia respeito à carência defuncionários. Por ocasião da inauguração da Colônia, em 1903, uma equipe próxima à prevista pela lei foi nomeada e enviada para a Colônia. M as segundo o relatório do Capitão Barros:

0 afastamento de diversos funcionários que se licenciaram, de fim de 1903 até março de 1904, deu ensejo a que ficassem acéfalos al guns cargos e que fossem outros acumulativamente exercidos pel os funcionários que permaneceram no serviço. É bem de ver, que do provimento de todos os cargos por pessoal idôneo dependeo funcionamento regular, harmônico enormal de todas as instituições públicas e particulares.

0 isolamento em que eram colocados os condenados na I l ha G rande poderia ser útil às intenções das autoridades de controlá-los e reedu cá-los, masjunto com eles ficavam também em extremo isolamento osfuncionários, quenão davam mostras de adaptação ao sistema. A comunicação dos que moravam em D ois Rios com o resto do mundo era precária. N ão havia uma linha telefônica quecomunicasse a C olônia com o continente. A falta detransportes era grande econtava-se apenas com um navio, o República, 
quefazia apenas duas viagens mensais. 0 resultado era a falta defuncionários, acumulação, improvisação e grande rotatividade em praticamente todos os cargos. ${ }^{33} \mathrm{~N}$ o período anterior (1904-1905), o diretor Guilherme Augusto da Silva acumulava os cargos de diretor, vice-diretor e médico; 0 feitor exercia as funções do escriturário e o guarda, do porteiro. Por ocasião do relatório citado, encontravam-se de licença, sem substitutos, o porteiro, o chefe de fábrica e o professor. 0 cargo de mestre de oficinas não tinha sido preenchido.

0 novo decreto reiterava a preocupação com o trabalho produtivo, uma vez que o produto do trabal ho dos internados ainda era previsto como sendo parte da receita das Colônias e do pecúlio a ser entregue na saída. Continuava a preocupação com a recuperação pela educação e pelo trabaIho. N ão obstante, podemos deduzir que, na ausência de médicos, professores, horticultores, agrônomos, chefes de fábrica e mestres de oficina, os objetivos legislados encontravam-se muito longe de serem cumpridos. Segundo o relatório:

Os trabalhos não têm obedecido aos verdadeiros preceitos da agricultura moderna, pois que a Colônia ressente-se da falta de um chefe de cultura, que possuindo o respectivo curso, ministre aos detentos instruções simples e práticas sobre a natureza do solo e sua produção (...).

Além da falta de funcionários especializados, o relatório menciona a precariedade das instalações. O s novos regulamentos determinavam quea Colônia deveria manter os indivíduos separados de acordo com causa de recolhimento, sexo eidade. Passavam a ser enviados para a Colônia todos os menores entre 9 e 14 anos, "inculpados criminalmente", que fossem órfãos, abandonados, ou julgados como tendo agido sem discernimento. Segundo o regulamento, os internos deveriam ser isolados em três grupos, respeitando suas idades (maiores de 21 anos; menores dessa idade; menores entre 9 e 14 anos). Era previsto ainda que enquanto não fosse criada uma colônia correcional destinada às mulheres, deveriam ser elas recolhidasà Colônia Correcional deD ois Rios, em seções isoladas e com disciplina e trabalho compatíveis com suas condições individuais. Segundo o diretor da Colônia, a manutenção dos reclusos em ambientes isolados dependia de instalações adequadas, com as quais não se contava: 
Faz-se mister que sejam completados o quanto antes os alojamentos destinados a garantir a separação dos internados, conforme as idades, as índoles e a causa da internação desses transviados sociais cuja separação, judiciosa e criteriosamente preceituam os arts. 35 e 37 do regulamento vigente (...).

O shomens, mulheres e criançasque eram enviados à Il ha precisavam, para se tornarem trabalhadores dignos, de serem tratados por médicos e enfermeiros, poiseram portadores desífilis, reumatismo, anemia, irritações intestinais, e outras mazelas. $\mathrm{N}$ em sempre havia médicos, os enfermeiros não eram suficientes e tanto a enfermaria quanto a farmácia foram instaladas precariamente na antiga senzala da Fazenda D ois Rios. Conforme 0 relatório:

$\mathrm{N}$ ão havendo na Colônia enfermaria própria para mulheres, têm sido as detentas que adoecem, tratadas na mesma enfermaria dos homens, para 0 que se fez preciso um tabique. (...) a enfermaria atual está mal situada e pobremente instalada. Fica ao péde uma montanha, de onde há umidadee é encravada entre um alojamento e outras dependências. 0 soalho é assente em barrotes colocados no chão, constituído este deareiaúmida. (...) E como se não bastasse a promiscuidade resultante do fato de serem homens e muIheres tratados em uma mesma sala, maior promiscuidade os aguarda e esta consiste em servirem-se uns e outros do mesmo aparel ho sanitário e de uma mesma banheira (...).

A questão da superlotação, que era uma constante nas demais colônias correcionais, foi, em parte, resolvida neste primeiro momento. A C olônia Correcional de Dois Rios, em seu primeiro ano dispunha detrêsalojamentos, com lotação para 135 detentos, o queera suficiente para o número de pessoas para lá enviadas. M as as instalações não eram apropriadas para manter os reclusos em ambientes separados segundo sexo, crime e idade. A fal ta de recursos, de funcionários e de instalações adequadas, portanto, aparecem nos relatórios oficiais como sendo as principais causas a minar os objetivos mais nobres estabelecidos pelas autoridades. 


\section{Para além da falta de verbas: pocilgas, trabalho escravo e mulheres vagabundas}

M as a defasagem entre lei e aplicação da lei também contou com um aspecto importante que precisa ser considerado: a arbitragem no cumprimento da lei pelas autoridades locais responsáveis. Por mais detal hados que fossem os regulamentos e por maior que fosse o controle por parte de autoridades competentes, a implementação da rotina na Colônia dependia em grande partedos diretores, funcionários e dos próprios indivíduos que para lá eram enviados. M esmo se consideradas as carências administrativas, a resolução de onde priorizar recursos cabia sempre ao diretor.

Em alguns casos, o próprio texto da lei era burlado, sem maioresconseqüências. Segundo o regulamento, por exemplo, deveria haver, em D ois Rios, duas escolas, sendo uma destinada para menores entre 9 e 14 anos e outra para maiores. No relatório citado, lemosque, em 28 de abril de 1904, foi inaugurada uma escola que matriculou apenas filhos de funcionários, não sendo possível matricular os menores infratores por falta de local apropriado.

G rande parte da rotina da Colônia pode ser atribuída à percepção que tinham as autoridades locais de sua função e, esta, estava longe de reiterar 0 texto da lei. D entre as disposições presentes em praticamente todas as leis do período, havia a de queas colônias deveriam despertar nos internos o sentimento de liberdadee os hábitos da auto-coerção. As práticas descritas, entretanto, mostravam que o tratamento dado ao interno estava longe de ser respeitoso. U m dos aspectos que chama a atenção no relatório do capitão Barros é a falt ta de condições mínimas de higiene, tão valorizadas pelas autoridades governamentais no governo de Rodrigues Alves, e que, não pode ser atribuída exclusivamente às carências materiais de infra-estrutura, pois o cuidado com as pocilgas parecia ser maior do que aquele com os correcionais. N o mesmo relatório lemos, por um lado, que os alojamentos se ressentiam de condições higiênicas, dispondo cada um deles apenas de uma latrina e de uma pequena pia com torneira e, por outro, que, com enormetrabalho, uma pocilga assaz espaçosafora construída, em lugar apropriado, eobedecendo as principais regras das pocilgas modernas.

0 trabalho deveria ser oferecido ao detento para sua reabilitação moral, a partir do aproveitamento das próprias aptidões de cada interno. M as, de 
acordo, ainda, com o relatório do capitão Barros, o pequeno número de internos era absorvido em serviços internos, como refeitório, cozinha, capinagem, faxina, reparos, consertose manutenção da estrada, não sobrando tempo para que eles trabalhassem em hortas e oficinas. 0 serviço de cozinha e faxina em al guns decretos ficava a cargo dos internos, mas em outrosnão. 0 decreto-lei de1902, por exemplo, previa cozinheiroseserventes entre o grupo de funcionários a ser empossado. $M$ as, evidentemente, a requisição de cozinhei ros eserventes não parece ter sido uma demanda dos dirigentes da Colônia, que sempre utilizaram maciçamente os internos como mão-de-obra servil nestes tipos detrabal ho. Como osinternos eram deslocados para serviços domésticos, não eram produzidos na Colônia produtos da agricultura, fábricas e oficinas que poderiam reverter para os internos sob a forma de um pecúlio.

Entre 1893 e 1903, as leis foram "qualificando" os indivíduos e designando instituições próprias e tratamentos especiais para el es: os menores deveriam ser identificados de acordo com a idade (menores de 21 anos e menores entre 9 e 14 anos) e mulheres deveriam ser separadas dos homens. No decreto de 1893, por exemplo, para a Colônia deveriam ser enviadososindivíduos de qual quer idadee sexo que fossem julgados como pertencentes às classes descritas. D ez anos mais tarde, o decreto de 1903 estabelecia a separação entre indivíduos do sexo masculino, mulheres e menores abandonados.

N o quetangeàsmulheres, alei nada dizia sobrea prostituição ou sobre "mulheres vagabundas". São citados explicitamente os ébrios, mendigos, vadiosecapoeiras. A partir dos relatóriosministeriais de 1904, 1905 e1906, é possível traçar um perfil aproximado daqueles que eram enviados para a Colônia Correcional de D ois Rios, e observamos, com grande surpresa, que havia um número grande de mulheres naquele estabelecimento. ${ }^{34}$ Podemos deduzir que prostitutas eram enviadas à Colônia porque tinham ocupações que eram "manifestamente ofensiva da moral e dos bons costumes" ou porque "quebravam o termo de bem viver," termo ainda mantido nos relatórios ministeriais deste período. 0 silêncio da lei sobre o "crime" da prostituição permitia uma liberdadeainda maior das autoridades locaisno tratamento imputado às mulheres. 
No relatório ministerial de 1905, por exemplo, lemos que em 1904 havia na Colônia 94 internos, "inclusive 30 mulheres vagabundas". $0 \mathrm{~s}$ homens, fossem eles condenados por serem bêbados, mendigos, vadios, capoeiras e ladrões, eram citados no relatório como sendo "homens" ou detentos "do sexo masculino". As mulheres, entretanto, não eram mulheres simplesmente, elas eram "mulheres vagabundas". No relatório do capitão Barros, a mesma terminologia é utilizada:

Esses alojamentos têm lotação para 135 detentos, sendo um de 70, um de 40 e o outro de 25. No primeiro eterceiro estão al ojados os correcionais do sexo masculino e no segundo as mulheres vagabundas (em no de 32 presentemente). (...) Presentemente o número de detentos é de 94, sendo 1 sentenciado e 93 correcionais, inclusive 30 mulheres vagabundas.

A capacidade de lidar com estas mulheres aparecia como um problema para o diretor, que, em outra passagem declarava:

Julgo de necessidade eliminar-se 0 art. $7^{\circ}$ das disposições provisórias ao referido regulamento, instalando-se desdejá uma colônia exclusivamentedestinada a mulheres. Isso interessa à moral do estabelecimento, onde residem famílias, além do que não podem aquelas mulheres ser aqui convenientemente aproveitadas em serviços compatíveis com as suas condições individuais.

Apesar da reclamação do diretor, quenão encontrava formas de aproveitar o serviço das mul heres convenientemente, não só elas eram, aparentemente, as únicas a dar algum lucro para o estabelecimento, pois eram responsáveis pela lavagem de roupas e pela confecção de vestimentas, colchas, lençóis, fronhas, aventais, toal has eassim por diante, como a atribuição a elas destas atividades parecia estar determinada a priori.

Para compreendermos a violência existente na Colônia, também não podemos nos ater ao que era previsto na lei. Se prestarmos a atenção de como a lei determinava o sistema de penas imposto aos faltosos, podemos verificar que o controle foi pensado a partir do corte dos benefícios, ou seja, privação do trabalho emulta sobreo pecúlio. Como os benefícios não existiam, a base de coerção certamente se pautava por outros critérios. Embora não tenhamos relatos dos castigos no período, eles certamentenão poderiam corresponder ao estabelecido pela lei. ${ }^{35}$ 


\begin{tabular}{|c|c|c|c|}
\hline & 1903 & 1904 & 1905 \\
\hline $\mathrm{N}$ o de internos & 81 & 94 & 134 \\
\hline Pena & $\begin{array}{l}39 \text { sentenciados } \\
42 \text { correcionais }\end{array}$ & $\begin{array}{l}1 \text { sentenciado } \\
93 \text { correcionais }\end{array}$ & $\begin{array}{l}12 \text { furto } \\
41 \text { embriaguez e } \\
\text { vagabundagem } \\
81 \text { quebra do termo } \\
\text { de bem viver }\end{array}$ \\
\hline Sexo & $\begin{array}{l}73 \text { homens } \\
9 \text { mulheres }\end{array}$ & $\begin{array}{l}64 \text { homens } \\
30 \text { mulheres }\end{array}$ & $\begin{array}{l}61 \text { homens } \\
73 \text { mulheres }\end{array}$ \\
\hline Idade & & & $\begin{array}{l}108 \text { adultos } \\
24 \text { entre } 17 \text { e } 21 \text { anos } \\
2 \text { entre } 14 \text { e } 17 \text { anos }\end{array}$ \\
\hline $\mathrm{N}$ acionalidade & & & $\begin{array}{l}110 \text { brasileiros } \\
17 \text { portugueses } \\
7 \text { outras }\end{array}$ \\
\hline
\end{tabular}

N o quetange às colônias correcionais, em que pese a importância das leis decretadas, seria importante destacar a influência do pensamento positivistanas práticas láinstaladas. ${ }^{36} \mathrm{~N}$ a Colônia C orrecional da Ilha G rande, os internos, ao chegarem, eram matriculados em um livro, em que ficavam registrados não só nome, filiação, naturalidade, idade, estado e religião, mas também cor, altura, dados antropométricos e todos os sinais possíveis. O s sentenciados não eram classificados apenas em relação a seu crime, mas também segundo traços biológicos. Procurava-se compreender a relação entre a contravenção ou crime e natureza biológica do detento. M esmo nos decretos citados, podemos ler que apesar de os médicos terem como função o exercício da profissão da medicina, também a eles cabia curar as almas, proferindo ensinamentos morais, quando possível. Em muitos casos, os médicos foram a segunda autoridade na colônia, sendo o substituto imediato do diretor. A base da reabilitação, na época, era pensa- 
da, portanto, em termos de isolamento etrabalho, mastambém deinstrução moral e religiosa.

N ão podemos deixar de lembrar, neste caso, de pensadores como $M$ iguel Lemos eTeixeira $M$ endes, que levantaram forte crítica às leis que classificavam vadiagem como crime, uma vez que, para eles, a vadiagem estava associada à burguesia e às classes médias, estas sim consideradas criminosas (Lemos \& M endes 1902:15-17):

(... ) A léga-se que a abolição do regimen escravocrata introduzirá na sociedade uma massa de hôomens que, estando acostumados à escravidão, recuzarão trabalhar desde que fôrem livres e passarão a engrossar o número dos vagabundos. (... ) Para conjurar esses males planeja-se então um regulamento que classifique a vagabundagem, ou antes a dezocupação, como um delito que ficará sob a alçada da autoridade civil. Por outro lado, o mesmo regulamento traçará régras de locação de serviç̧os, dando garantias aos patrões contra a inconstância dos proletários (... ).

Para desvanecer este tecido de sofismas importa reconhecer, em primeiro lugar, que a vagabundágem, a recuza ao trabalho, não é um vício peculiar às classes póbres. A contemplação da sociedade demonstra não só queo maior número de vagabundos éfornecido pela burguesia, mas ainda que são esses os vagabundos mais prejudiciais. (... ).

0 único vagabundo para eles éo pobre sem trabalho, ou o mendigo, cuja dignidade a grosseria contemporânea não compreende, mas que 0 positivismo consagra, sistematizando a inspiração católica e sancionando as anticipações poéticas a este respeito.

Embora nos períodos subseqüentes, a interven ção de colonos e pescadores que vivem nal lha Grande sobre o perfil do presídio tenha sido bem maior, já nos primeiros anos ela sefez presente, pois devido ao isolamento da ilha os guardas e policiais que lá trabalharam sempre foram recrutados entre moradores locais. As orientações oficiais e administrativas de lidar com crime conviveram com desejos de punição baseados em julgamentos moraismundanos que permeavam a sociedade. 0 satores desta história respondem a diversas influências e determinações, sendo que não seria errado afirmar queo velho anseio por retribuição evingança coexistecom novas formas de se pensar a justiça, reiterando antigas tradições e formas de interação sociais. 
Em outras palavras, nos relatórios oficiais o diagnóstico apresentado sobre os problemas do estabelecimento sempre recai na falta de verbas, ${ }^{37}$ mas o que procurei mostrar a partir da análise destes mesmos relatórios foi que apesar de todo o detalhamento de leis e regulamentos, a Colônia Correcional de D ois Rios não só esteve longe de estar subordinada ao regime técnico disciplinar previsto, como, em muitos aspectos, reproduzia hábitos, idéias e costumes da época.

\section{Conclusão}

A Colônia Correcional de D ois Rios foi criada segundo um código penal de cunho liberal, em que se procurava ordenar e civilizar o sistema prisional existente, a partir de normas e regulamentos minuciosos a serem seguidos. M as, como vimos, a crença de quea racional idade inerente à lei seria capaz de se impor sobre desigual dades sociais urbanas, conflitos, preconceitos e mazelas sociais, legitimou uma série de políticas públicas autoritárias.$^{38} \mathrm{~A}$ promulgação da lei por si só não foi capaz de guiar deforma neutra e competente as políticas públicas. Além disso, a extensão do encarceramento e do modelo disciplinar para as "classes perigosas" esteve fortemente vinculado ao ideário liberal. N ão podemos estranhar, portanto, que gatunos, capoeiras, ladrões, falsários, prostitutas e presos em geral fossem, em sua maioria, defensores da monarquia. ${ }^{39}$

Ainda assim, é possível constatar quenem o pensamento liberal, com sua defesa de regeneração por meio de práticas impessoais, nem o ideário positivista, que denunciava a opressão de novas classes e resgatava a dignidade daqueles que perambulavam na cidade sem trabalho, pareciam ser capazes de obter os resultados desejados. 0 s relatórios obtidos no final dos dois períodos analisados não deixam dúvidas de que a política de encarceramento adotada não gerou melhoria significativa nos métodos prisionais. Se considerados os objetivos e regulamentos expressos na lei, o de reabilitar os internos para a vida social, propiciando formação especializada e experiência positiva com o trabal ho, as duas iniciativas de criação daC olônia podem ser consideradas um completo fracasso. Entretanto, é difícil decretar o fracasso de instituições que estabeleceram os alicerces de práticas que se mantiveram presentes por praticamente um século. 
Q uanto mais chegamos perto das práticas desenvolvidas nos cárceres nos damos conta de que precisamos melhor compreender o porquê do distanciamento tão grande entre estas práticas e as normas e regulamentos estabelecidos. A preocupação com pocilgas em detrimento de instalações mínimas de higiene, o tratamento discriminatório e preconceituoso em relação ao "contraventor" ou "criminoso", a utilização de detentos em trabalho servil, estes são traços do passado que têm certas continuidades com os tratamentos proporcionados aos presos ainda nos dias de hoje. No caso da I lha G rande, neste primeiro momento, a lógica de regenerar pela disciplina e pelo trabalho e pela educação o "enfermo moral" esteve longe de substituir a lógica punitiva de períodosprecedentes, queinfligia aos detentos castigos corporais e humilhantes. 0 desejo de vingança e retaliação que povoava as praças públicas medievais não parece ter sido completamente abolido pelo novo sistema que fora instalado.

As colônias analisadas, embora implementadas a partir dos decretos do legislativo edo poder executivo, e por eles configuradas, não podem ser pensadas como resultado exclusivo da implementação destes atos e leis. 0 funcionamento das instituições correcionaisfoi resultado de uma negociação complexa em que as proposições dos reformadores se confrontavam com a prática dos juízes, decisões dos administradores locais e desejos e preocupações da sociedade em geral. Legisladores, policiais, juízes, religiosos e diversos grupos de interesse demarcaram seu lugar no processo que começa a ser aqui descrito. $\mathrm{N}$ em sempretemos o testemunho detodos esses atores, mas, sem dúvida, algumas marcas encontradas denunciam a presençadelesna dinâmicaanalisada. ${ }^{40} 0$ s diretores e os funcionários trouxeram com eles valores, preconceitos, ehábitos da sociedade em que se inseriam.

\section{Fontes}

Relatórios do M inistério da Justiça e N egócios Interiores:

Relatório do M inistro de Justiça e N egócios Interiores, D r. Antônio Gonçalves Ferreira, ao Presidente da República, Sr. Prudente de M oraes, de abril de 1896;

Relatório do M inistro de JustiçaeN egócios Interiores, D r. Amaro Cavalcanti, ao Presidente da República, Sr. Prudente de M oraes, de março de 1897; 
Relatório do M inistro de Justiça e N egócios Interiores, D r. J. J. Seabra, ao Presidente da República, Sr. Rodrigues Alves, de março de 1905;

Relatório do M inistro de Justiça e N egócios I nteriores, D r. J. J. Seabra, ao Presidente da República, Sr. Rodrigues Alves, de março de 1906;

Relatório do Diretor da Colônia Correcional Dois Rios, Capitão Francisco Siqueira do Rego Bastos, ao Chefe de Polícia do Distrito Federal, anexo ao relatório do M inistro de Justiça e N egócios I nteriores, D r. J. J. Seabra, ao Presidente da República, Sr. Rodrigues Alves, de março de 1905.

\section{Legislação citada}

Constituição de 1824.

Código Criminal de 1830.

D ecreto $n .0847$, de 11 de outubro de 1890, Código Penal.

D ecreto-Lei n.․ 145, de 11 de julho de 1893.

D ecreto $n .0$ 1.794, de 11 de setembro de 1894 .

Lei $n .0$ 429, de 10 de dezembro de 1896.

D ecreto $n .0$ 2.432, de 12 de janeiro de 1897.

Lei $n . .947$ (Alfredo Pinto), de 29 de dezembro de 1902.

D ecreto-Lei $n .0$ 4.753, de 28 de janeiro de 1903.

D ecreto n. 6.994, de 19 de junho de 1904.

\section{Bibliografia}

BAN D EIRA FILH O, Antonio H erculano de Souza. A questão penitenciária no Brazil. Rio de Janeiro: Typ. de J. D . de Oliveira, 1881.

BAU M AN , Zygmunt. G lobalização: As conseqüências humanas. Rio de Janeiro: Jorge Zahar Ed., 1999.

BRETAS, M arcos. A guerra das ruas: povo e polícia na cidade do Rio de Janeiro. Rio de Janeiro: IUPERJ, 1988.

CARVALH O, José M urilo de. O s bestializados: o Rio de Janeiro ea República que não foi. São Paulo: Companhia das Letras, 1987. 
CH ALH O UB, Sidney. Cidade febril: cortiços e epi demias na Corte imperial. São Paulo: Companhia das Letras, 1996.

. Trabalho, lar ebotequim: 0 cotidiano dostrabalhadoresno Rio deJaneiro da Belle É poque. Campinas: Editora da Unicamp, 2001.

FO U CAU LT, M ichel. Surveiller et punir: naissancedela prison. Paris: Gallimard, 1975. KOWARICK, Lúcio. Trabal ho e vadiagem: a origem do trabal ho livre no Brasil. São Paulo: Paz eTerra, 1994.

LEM OS, M iguel \& M EN DES, Teixeira. A liberdade espiritual ea organização do trabalho. Rio de Janeiro: I greja e Apostolado Pozitivista do Brasil, 1902.

LIM A, Kant de \& LIM A, M agali Alonso de. Capoeira e cidadania: negritude e identidadeno Brasil republicano. Revista deAntropologia, n. 34, pp. 143-82, 1991. M ELLO , Carl Egbert H ansen Vieira de. Apontamentos para servir à H istória fluminense: Ilha Grande, Angra dos Reis. Angra dos Reis: C onselho M unicipal de Cultura, Prefeitura de Angra dos Reis, 1987.

M ORRIS, N orval \& ROTH M AN , D avid J. The O xford H istory of the prison: the practice of punishment in western soci ety. N ew York: O xford U niversity Press, 1995.

PAM PLON A, M arco Antonio. A historiografia sobre o protesto popular e sua contribuição para o estudo das revoltas urbanas. Estudos H istóricos, n. 17, 1996.

SALLA, Fernando. Asprisõesem São Paulo: 1822-1940. São Paulo: Annablume, 1999. SEVCEN KO , N icolau. Literatura como mi ssão: ten sões sociais e criação cultural na Primeira República. São Paulo: Brasiliense, 1983.

. H istória e memória: o caso do Ferrugem. Revista Brasileira de História. Rio de Janeiro, v. 23, n. 46, pp. 271-295, 2004.

. A construção da violência: 0 caso da Ilha Grande. In: PRAD 0, M anhães Rosane (ed.). Ilha Grande: do Sambaqui ao turismo. Rio de Janeiro: ED U ERJ, 2004 (no prelo).

SOARES, C arlos Eugênio Líbano. A negregada instituição: os capoei ras no Rio de Janeiro. Coleção Biblioteca Carioca. Rio de Janeiro: Secretaria M unicipal de Cultura, 1994.

TO CQ UEVILLE, Alexis de. É crits sur le système pénitentiaire en France et à I'étranger. O euvres complètes. Paris: G allimard, 1984.

WACQUANT, Loïc J. D. Os condenados da cidade. Rio de Janeiro: Revan, FASE, 2001. 


\section{Notas}

${ }^{1}$ D ecreto-Lei n. 145, de 11 de julho de 1893.

2 Ver, por exemplo, KOWARICK, Lúcio. Trabalho evadiagem: a origem do trabal ho livre no Brasil. São Paulo: Paz eTerra, 1994 e CH ALH O U B, Sidney. Trabal ho, lar ebotequim: o cotidiano dostrabal hadores no Rio de Janeiro da BelleÉ poque. Campinas: Editora daU nicamp, 2001.

${ }^{3}$ Estas análises estão em consonância com aquelas que atribuem às prisões e ao aparato político-administrativo penal queseforma a partir do século XVIII objetivos muito mais amplos do que os de isolar, punir ou reabilitar infratores da lei, fortalecendo o poder estatal ou o poder das elites, seja simbólica ou materialmente. A própria justiça criminal é compreendida como sendo um instrumento de dominação. FO U CAU LT, M ichel. Surveiller et punir: nai ssance dela prison. Paris: G allimard, 1975 eBAU M AN , Zygmunt. Globalização: as conseqüências humanas. Rio de Janeiro: Jorge Zahar Ed., 1999.

${ }^{4}$ TO CQ U EV ILLE, Alexis de. É crits sur le système pénitentiaire en France et à l'étranger. 0 euvres complètes. Paris: Gallimard, 1984, p. 98.

${ }^{5}$ FO U CAU LT, M ichel, op. cit.

${ }^{6}$ SALLA, Fernando. As prisões em São Paulo: 1822-1940. São Paulo: Annablume, 1999, p. 44.

${ }^{7}$ Para uma descrição detal hada dos sistemas penitenciários estabel ecidos pelos estados de N ova Iorque e Pensilvânia nos anos vinte do século dezenove, ver M ORRIS, N orval \& ROT H M AN , D avid J. TheO xford $\mathrm{H}$ istory of theprison: thepractice of punishment in wetern society. N ew York: 0 xford U niversity Press, 1995, pp. 105-106.

${ }^{8}$ Estas observações são reiteradas mais tarde por Foucault, em Vigiar e punir, onde, ao analisar as transformações ocorridas no sistema penal, ao longo do século XIX, afirma que a recuperação do criminoso passa a exigir uma estratégia disciplinar bastante desenvolvida. As novas edificações deveriam permitir que os presos ficassem isolados uns dos outros e tivessem seus passos vigiados pel os policiais durante todo o tempo, o que possibilitaria um controle bem maior destes por parte dos sistemas disciplinares. Entre as medidas a serem adotadas, destacava-se, primeiro, a separação dos presos de acordo com tipos de delitos, segundo, a melhoria da higienee alimentação e, terceiro, a substituição do poder do carcereiro pelas leis e métodos disciplinares. FO U CAU LT, M ichel, op. cit.

${ }^{9}$ Alexis de Tocqueville não só descreveu os diversos sistemas penitenciários visitados por ele entre 1831 e 1832, como deixou várias cartas e relatórios em que defende o sistema utilizado na Filadélfia e faz propostas de modificações do sistema penitenciário francês. Ver TO CQ U EVILLE, Alexis de, op. cit., pp. 94-100.

${ }^{10}$ Segundo Fernando Salla, a primeira casa correcional do Brasil foi criada em 1834, a partir de uma pequena dependência do Q uartel daTropa de Primeira Linha, em São Paulo. As duas seguintes foram criadas no Rio de Janeiro e em São Paulo, em 1850 e 1852 respectivamente. SALLA, Fernando, op. cit., pp. 33-111.

${ }^{11}$ SALLA, Fernando, op. cit., pp. 59-66. 
${ }^{12}$ BAN D EIRA FILH O, Antonio H erculano de Souza. A questão penitenciária no Brazil. Rio de Janeiro: Typ. de J. D. de O liveira, 1881.

${ }^{13} \mathrm{~A}$ lei 2.033, de 20 de setembro de 1871, transferia da autoridade policial para o juiz a decisão sobre a prisão preventiva no caso de crime afiançável. Sobre o tema, ver SALLA, Fernando, op. cit., p. 118.

${ }^{14}$ SALLA, Fernando, op. cit., p. 132.

${ }^{15}$ D ecreto legislativo no 145 , de 11 de julho de 1893:

"Art. $1^{\circ} \mathrm{O}$ G overno fundará uma colônia correcional no próprio nacional Fazenda da Boa Vista, existentena Parayba do Sul, ou onde melhor Ihe parecer, deven do aproveitar, além daquela fazenda, as colônias militares atuais que a isso se prestarem, para correção, pelo trabalho dos vadios, vagabundose capoeiras que forem encontrados, e como tais processados na C apital Federal.

Art. $2^{\circ}$ São compreendidos nessas classes:

$\S 1^{\circ} 0$ s indivíduos de qual quer sexo e qualquer idade que, não estando sujeitos ao poder paterno ou sob a direção de tutores ou curadores, sem meios de subsistência, por fortuna própria, ou profissão, arte, ofício, ocupação legal e honesta em que ganhem a vida, vagarem pela cidade na ociosidade."

${ }^{16}$ Ver Bretas 1988.

${ }^{17}$ Capítulo XII: D os M endigos eÉ brios.

"Art. 391. M endigar, tendo saúde e aptidão para trabal har:

Pena - de prisão celular por oito a trinta dias. (... ).

Art. 393. M endigar fingindo enfermidades, simulando motivo para armar à comiseração, ou usando de modo ameaçador e vexatório:

Pena - de prisão celular por um a dois meses. (... ).

Art. 396. Embriagar-se por hábito, ou apresentar-se em público em estado de embriaguez manifesta: Pena - de prisão celular por quinze a trinta dias.(... ).

Capítulo XIII: D os Vadios e C apoeiras

Art. 399. D eixar de exercitar profissão, ofício, ou qual quer mister em que ganhe a vida, não possuindo meios desubsistência e domicílio certo em que habite; prover a subsistência por meio de ocupação proibida por lei, ou manifestamente ofensiva da moral e dos bons costumes:

Pena - de prisão celular por quinze a trinta dias.

$\S 1$ 을 Pela mesma sentença que condenar o infrator como vadio, ou vagabundo, será ele obrigado a assinar termo de tomar ocupação dentro de 15 dias, contados do cumprimento da pena.

$\S 2$ O O s maiores de 14 anos serão recolhidos a estabelecimentos disciplinares industriais, onde poderão ser conservados até a idade de 21 anos.(...).

Art. 400. Se o termo for quebrado, o que importará reincidência, o infrator será recolhido, por um a três anos, a colônias penais que se fundarem em ilhas marítimas, ou nas fronteiras do território nacional, podendo para esse fim ser aproveitados os presídios militares existentes.

Parágrafo único. Se o infrator for estrangeiro será deportado. 
Art. 401. A pena imposta aos infratores, a que se referem os artigos precedentes, ficará extinta, se o condenado provar superveniente aquisição de renda bastante para sua subsistência; e suspensas, se apresentar fiador idôneo que por ele se obrigue.

Parágrafo único. A sentença que, a requerimento do fiador, julgar quebrada a fiança, tornará efetiva a condenação suspensa por virtude dela.

Art. 402. Fazer nas ruas e praças públicas exercícios de agilidade e destreza corporal conhecidos pela denominação capoeiragem; andar em correrias, com armas ou instrumentos capazes de produzir uma lesão corporal, provocando tumultos ou desordens, ameaçando pessoa certa ou incerta, ou incutindo temor de al gum mal:

Pena - de prisão celular por dois a seis meses.

Parágrafo único. É considerado circunstância agravante pertencer o capoeira a alguma banda ou malta. Aos chefes, ou cabeças, se imporá a pena em dobro.

Art. 403. No caso de reincidência, será aplicada ao capoeira, no grau máximo, a pena do art. 400 .

Parágrafo único. Se for estrangeiro, será deportado depois de cumprida a pena."

${ }^{18} \mathrm{O}$ artigo 404 do Código Penal não poderia ser mais explícito: "Art. 404. Senesses exercícios de capoeiragem perpetrar homicídio, praticar al guma lesão corporal, ultrajar o pudor público e particular, perturbar a ordem, a tranqüilidade ou segurança pública, ou for encontrado com armas, incorrerá cumulativamente nas penas cominadas para tais crimes."

${ }^{19}$ Sobreas práticas da capoeira, ver, entreoutros, LIM A, K ant de\& LIM A, M agali Alonso de. Capoeira e cidadania: negritude e identidade no Brasil republicano. Revista deAntropologia, n. 34, pp. 143-82, 1991; CARVALH O, José M urilo de. 0 sbestializados. o Rio de Janeiro e a República que não foi. São Paulo: Companhia das Letras, 1987 e SO ARES, Carlos Eugênio Líbano. A N egregada Instituição: os capoeiras no Rio de Janeiro. Coleção Biblioteca Carioca. Rio de Janeiro: Secretaria M unicipal de Cultura, 1994.

${ }^{20}$ SEV CEN KO , N icolau. Literatura como missão: tensões sociais e criação cultural na Primeira República. São Paulo: Brasiliense, 1983; PAM PLO N A, M arco Antonio. A historiografia sobre o protesto popular e sua contribuição para o estudo das revoltas urbanas. EstudosH istóricos, n. 17, 1996 e CH ALH O U B, Sidney. Cidadefebril: cortiçose epidemias na Corte imperial. São Paulo: Companhia das Letras, 1996.

${ }^{21}$ Sobre o tratamento dado aos capoeiras, ver SO ARES, op. cit., pp. 247-309.

${ }^{22} \mathrm{~A}$ exclusão de determinados setores da população dos direitos à cidadania arrasta-se até os dias atuais, sendo muitos os pontos em comum entre os ébrios e vadios do início do século e aqueles que são contemporaneamente conhecidos como pertencentes à "underclass". Segundo Wacquant, este seria um novo termo nebuloso que procura dar conta de um estilo de vida e valores "disfuncionais" que levariam um grupo social ao desemprego e ao recurso crônico à assistência social. WAC Q U AN T, Loïc J. D . O scondenados da cidade. Rio de Janeiro: Revan, FASE, 2001, p. 94.

${ }^{23}$ D ecreto do executivo n. 1.794, de 11 de setembro de 1894.

${ }^{24}$ Relatório do M inistro de Justiça eN egócios Interiores, D r. Antônio G onçalves Ferreira, ao Presidenteda República, Sr. Prudente de M oraes, de abril de 1896. O s diversos relatórios ministeriais aqui citados fazem parte do acervo do Arquivo $\mathrm{N}$ acional. 
${ }^{25}$ Poucas informações há sobre o funcionamento da Colônia nesta sua primeira fase. Segundo $M$ ello, os primeiros diretores foram o $M$ ajor J oséR odrigues $C$ abral $M$ oyaeo $M$ ajor Antonio G onçal ves Barreiro, sendo que após a desativação, o alferes J oaquim R aymundo, antigo morador, passou a ser o responsável pela administração do local. M ELLO , Carl Egbert $\mathrm{H}$ ansen $\mathrm{V}$ ieira de. Apontamentospara servir à $\mathrm{H}$ istória fluminense: I lha $\mathrm{G}$ rande, Angra dos Reis. Angra dos Reis: Conselho M unicipal de Cultura, Prefeitura de Angra dos Reis, 1987, p. 91.

${ }^{26}$ Relatório do M inistro de Justiça e N egócios Interiores, Dr. Amaro C avalcanti, ao Presidente da República, Sr. Prudente de M oraes, de março de 1897. A comissão de inspeção foi composta pelos cidadãos J oséR amos da Silva Júnior, João Bernardes da C ruz Júnior e Antônio J oaquim Cordovil M auritz. O M inistro daJustiça e N egócios Interiores responsável pela decisão do fechamento foi Alberto Torres ea comissão nomeada por ele responsável por fazer o inventário do material deixado em $D$ ois R ios era composta por R aimundo Pereira Caldas e Antônio Joaquim Cordovil M auritz. A Colônia foi extinta através do decreto n. 2.432, de 12 dejaneiro de 1897 , em conformidade com $\S 5$ do artigo $2^{\circ}$ da Lei n. 429 de 10 de dezembro de 1896.

${ }^{27}$ Lei n. 628, de 28 de outubro de 1899, mais conhecida como Lei Alfredo Pinto, por ter sido o projeto inicial de autoria deste deputado.

${ }^{28}$ Citado por M ELLO , C arl, op. cit., p. 92.

${ }^{29}$ Relatório já citado do Capitão Francisco de Siqueira R ego Barros, diretor da CCDR entre 14/3/1904 e 26/2/1906.

${ }^{30} \mathrm{~A}$ Lei n. 947, de 29 de dezembro de 1902, autorizou a criação deuma ou mais colônias correcionais. 0 D ecreto-Lei n. 4.753, de 28 de janeiro de 1903 sancionou a Lei e aprovou o novo regulamento.

31 O D ecreto n. 6.994, de 19 de junho de 1904, estabeleceu novo regulamento para a Colônia.

${ }^{32}$ Este relatório do capitão Francisco de Siqueira Rego Barros encontra-se anexo ao Relatório encaminhado pelo M inistro de Justiça e N egócios Interiores, D r. J. J. Seabra, ao Presidente da República, em março de 1905.

${ }^{33}$ D e acordo com relatórios ministeriais os diretores da Colônia Correcional D ois Rios, entre defevereiro de 1903 efevereiro de 1906, foram capitão J oão Batista N eiva Figueiredo (9/9/1903 - 1/6/1904), GuilhermeAugusto da Silva(1/6/1904 - 3/3/1905), capitão Francisco deSiqueira Rego Barros (14/3/1905 - 26/2/1906), e oão Ernesto ClaudeSampaio. ${ }^{34} \mathrm{O}$ s dados obtidos nos relatórios não são coerentese, muitas vezes, encontramos referências a números no interior dos mesmos relatórios contraditórias. Ainda assim, para os objetivos deste trabalho éinteressante construirmos um perfil aproximado dos detentos. 35 Para compreender o processo de violência presente em anos subseqüentes, ver SAN TOS, M yrian Sepúlveda. A construção da violência: 0 caso da llha Grande. In: PRAD 0 , $M$ anhães Rosane (ed.). I lha Grande: do Sambaqui ao turismo. Rio de Janeiro: ED U ERJ, 2004 (no prelo).

${ }^{36}$ SALLA, Fernando, op. cit., p. 151. 
${ }^{37}$ Relatório do M inistro da Justiça e N egócios I nteriores, de 1907, sobre o ano anterior: "Este estabelecimento não preenche absolutamente os fins para que foi criado, havendo necessidade inadiável de dar-Ihe mais ativa e zelosa administração e provêlo de elementos indispensáveis ao seu bom funcionamento. $0 \mathrm{~s}$ alojamentos e demais dependências não obedecem a nenhum sistema penitenciário, nem comportam os correcionais ali existentes. Alguns deles são imprestáveis e o seu estado de ruína está reclamando reparos que não podem ser adiados. (...) Para esses reparos e outros melhoramentos faz-se mister que - C ongresso $\mathrm{N}$ acional vote o credito de 140:000\$, em queseacham orçadas as despesas." ${ }^{38}$ Esta denúncia tem sido feita por vários autores, ver, por exemplo, a afirmação de que a al egação de 'cientificidade', de neutralidade nas decisões administrativas, trouxe sempre em seu cerne a violência contra a cidadania. CH ALH O U B, Sidney, op. cit., pp. 20, 58. ${ }^{39}$ CARVALH O , José M urilo de, op. cit., p. 31.

${ }^{40}$ Para uma análise mais detalhada da relação entre o sistema carcerário da I lha G randee a população local, ver SAN TO S, 2004.

\section{Resumo}

0 artigo tem como objetivo investigar duas tentativas de implementação da Colônia Correcional de D ois Rios, na I lha G rande, durante os primeirosanos da era republicana. A pesar de propostas correcionais epráticas disciplinares de encarceramento serem implementadas em conformidadecom práticas que se difundiam em países europeus e nos Estados U nidos, elas tomaram no Brasil aspectosorganizacionais bem mais mundanos, em conformidade com objetivos, valores e crenças presentes entre as autoridades responsáveis pelo funcionamento das prisões e entre os próprios internos. O s documentos utilizados foram decretos do legislativo e do executivo, e diversos relatórios ministeriais, de chefes de polícia e diretores do presídio. Palavras-chave: Primeira República, Rio deJaneiro, I lha G rande, presídios, penitenciária, violência, crime

\section{Abstract}

The main objective of this article is to investigate the creation of a penitentiary establishment called "Colônia Correcional de D ois Rios", at IlhaG rande, Rio deJ aneiro, during thefirst years of theBrazilian Republic system. Although the disciplinary proposal and measures were related to ongoing practices that have been developed in European countries and in 
A prisão dos ébrios, Capoeiras e vagabundos no início da Era Republicana 169

the U nited States, they assumed a very particular aspect in Brazil, since the followed objectives, values and beliefs that were present amongst those who were responsiblefor thedirect administration of the prisons and theinterns. Key-words: First Brazilian Republic, Rio de Janeiro, I lha Grande, prisons, penitentiary, violence, torture, crime 